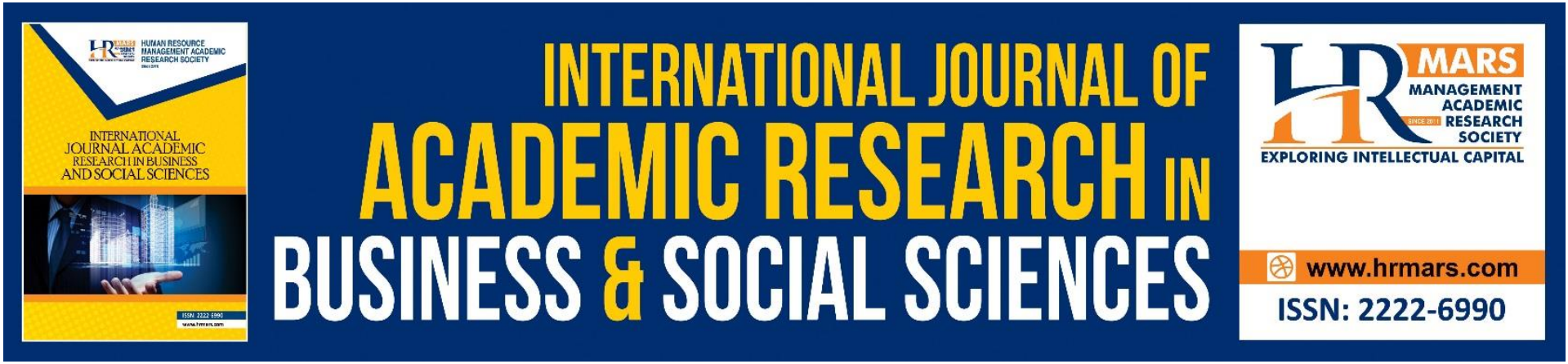

\title{
Self-Efficacy towards Health Risk among Graduates
}

\author{
K Yussof, SM Mohd Idris and N Abd Razak
}

To Link this Article: http://dx.doi.org/10.6007/IJARBSS/v12-i1/11898

DOI:10.6007/IJARBSS/v12-i1/11898

Received: 05 November 2021, Revised: 07 December 2021, Accepted: 25 December 2021

Published Online: 13 January 2022

In-Text Citation: (Yussof et al., 2022)

To Cite this Article: Yussof, K., Idris, S. M., \& Razak, N. A. (2022). Self-Efficacy towards Health Risk among Graduates. International Journal of Academic Research in Business and Social Sciences, 12(1), 983-993.

Copyright: (c) 2022 The Author(s)

Published by Human Resource Management Academic Research Society (www.hrmars.com)

This article is published under the Creative Commons Attribution (CC BY 4.0) license. Anyone may reproduce, distribute, translate and create derivative works of this article (for both commercial and non0-commercial purposes), subject to full attribution to the original publication and authors. The full terms of this license may be seen at: http://creativecommons.org/licences/by/4.0/legalcode

Vol. 12, No. 1, 2022, Pg. $983-993$

http://hrmars.com/index.php/pages/detail/IJARBSS

JOURNAL HOMEPAGE

Full Terms \& Conditions of access and use can be found at http://hrmars.com/index.php/pages/detail/publication-ethics 


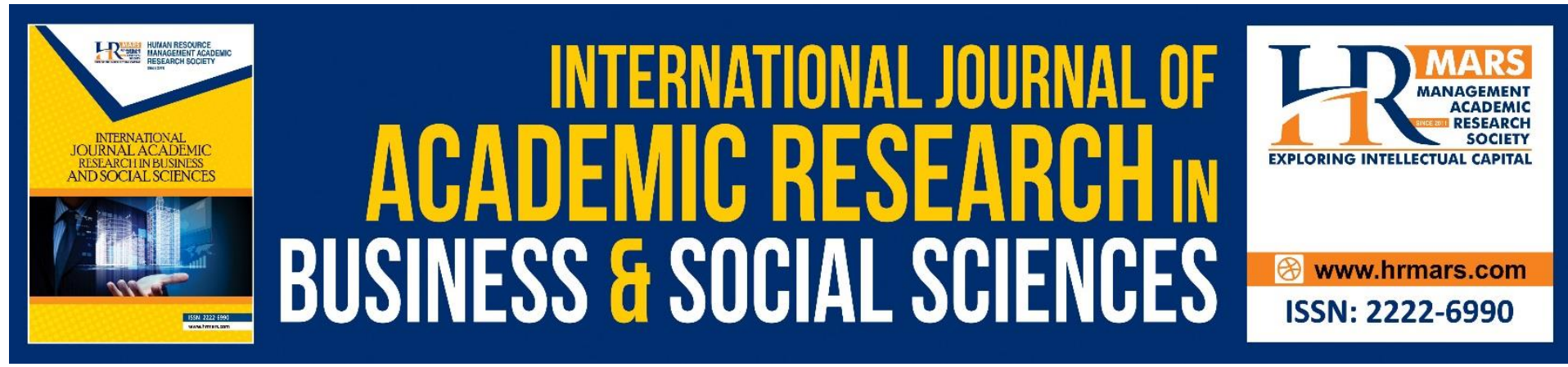

\title{
Self-Efficacy towards Health Risk among Graduates
}

\author{
K Yussof, SM Mohd Idris and N Abd Razak \\ Faculty of Business Management, University Technology MARA, Melaka, Malaysia \\ Corresponding Author Email (s): khairunnisayussof@uitm.edu.my \\ Contributing Authors: sitimusliha@uitm.edu.my, noraznira@uitm.edu.my
}

\begin{abstract}
One of the most intriguing topics in health risk research, as well as behaviour change, is the concept of behaviour change. Understanding the factors that influence behaviour change becomes critical for the organisation or community to ensure that behaviour change is properly addressed. However, changing one's behaviour is difficult due to a variety of external and internal barriers. The purpose of this study is to look at behavioural changes that can help prevent mental health risks such as depression among undergraduates. As a result, organisations must identify the factors that influence behaviour change in order to protect themselves from mental health risks such as depression among undergraduates. As a result, this study looks at the factors that influence behaviour change in terms of self-efficacy and action planning by partially adopting Health Action Process Approach (HAPA) Theory. This paper explains how the efficacy of students' can positively adapt changes of behavior towards preventing the risks of mental health risks such as depression as a first step in a bid to reduce the chances of having it. Finally, as an initial experiment, this study provides a conceptual framework for the role of self-efficacy and planning in assisting behaviour change among undergraduates in order to prevent mental health risks such as depression risk.

Keywords: Preventive Behaviour, Self-Efficacy, Undergraduates, Health Risk, Health Action Process Approach

\section{Introduction}

Promoting mental health and well-being is a critical component of the 2030 agenda for Sustainable Development. The World Health Organization (WHO) reported $10-20 \%$ of children and adults experienced health risks. As for the scope of health risks under this research will be focussing on mental health risks. $50 \%$ of mental health illnesses begin by the age of 14 and three-quarters by mid-20s (NHMS, 2018). Mental health risks are increasing daily. This disease keep on increasing day by day and has becomes the second most prevalent after non communicable disease and is potentially cluster as an urgency in the future. There are various types of mental health risks such as mental health risks such as depression, anxiety, bipolar disorder, and Schizophrenia (Bernama, 2018). Each of them has a unique effect, diagnosis, and treatments.
\end{abstract}


Mental health risks such as mental health risks such as depression can have a negative impact on an individual's overall well-being (Parikh et al.,2018). This disease able to effect an individual's productivity and ability to perform even routine chores. Additionally, (Khan et al, 2009) stated that individuals who have experienced mental illness also may have a tendency toward self-injury. This is because people's behaviours can alter according to their current circumstances (Ferrer \& Klein, 2015). Hazard or peril exits may have an effect on behaviour, influencing it to have either positive or bad consequences, depending on the individual's selfefficacy. Tahmassian and Moghadam (2011) claimed the self-efficacy is the individuals' behavior, think or feel which derived from their beliefs.

In Malaysia, mental health risks such as depression among undergraduates nowadays is alarming. The prevalence of this condition is increasing due to a lack of understanding of common mental problems, their causes, and consequences, as well as early warning signs of serious mental issues (Bernama, 2018). In addition, lack of social support from parents, teachers, or community exposes them to conflict and mental health risks such as depression. Moreover, the loss of a loved one and continuous financial hardships trigger sadness among college students. This is a depressive signal in the community. Hafidz (2014)claimed that people with mental health risks such as depression in Malaysia, as in many other countries, have an access treatment but they face huge difficulties in seeking help.

Even though the problem can be resolved with adequate treatment, there is a risk of it deteriorating or becoming serious if not addressed properly. Therefore, mental illness among undergraduates must be addressed because they are the country's future assets. Without an effective monitoring channel on this, the country shall face difficulties in having competent human capital in the future. Thus, it is quite desirable and necessary to research the preventive mental health risks such as depression behaviours undergraduates engage in on a regular basis. By identifying their conduct, the stakeholders involved can easily establish methods for strengthening the individual's well-being (Othman and Essau, 2019).

\section{Literature Review}

\section{Mental Health Risks such as Depression and Malaysian Undergraduates}

Mental health risks such as depression is the most commonly reported mental disease in Malaysia (NHMS, 2019). Mental health risks such as depression is a severe mental health issue that affects mood and pleasure. Changes in mood are accompanied by physical, emotional, and cognitive symptoms. Sadness, guilt, low self-esteem, and discontentment with life are all symptoms of mental health risks such as depression (De Aquino et al, 2018). WHO stated the level of mental health risks such as depression and can be classified as mild, moderate or severe. Decades ago, experts debated on the possibility of mental health risks such as depression in youngsters (Eriksson, Gökhan, and Stenius, 2021). However, changing times have shown that undergraduates are already showing signs of mental health risks such as depression. If mental health risks such as depression is not treated, undergraduates may commit suicide.

In Malaysia, the NHMS (2019) stated that about 2.3 percent from half a million people of the population suffered from mental health risks such as depression. Bernama (2018); Yee et al (2021) reported that currently the disease is impacting more on adolescents (younger age group). Undergraduates were identified as more stressed due to their juggling obligations. This causes an excruciating mental strain for the undergrads (Yee et al., 2021). Young age groups are defined as those who range of age from 16 to 21 years old. These ages usually be known as still striving for self-identity. This is expected to spark a massive conflict in 
themselves. Some may consider mental health risks such as depression less serious than school absence, smoking, or gangsterism. NHMS (2019) reported that about 424,000 children were found to have mental health. This is a worrying sign for future adolescent development of well-being.

It has become a prominent cause of morbidity and predicted to be one of the leading causes of disability globally by 2020 especially in high-income countries. The mental health risks such as depression's implication had increased in suicidal behaviour among young people aged 13 to 17 , with $10 \%$ of those surveyed in 2017 compared to $7.9 \%$ in 2012 (NHMS, 2018). As a result of the widespread frequency and morbidity, the researcher needs to examine mental health risks such as depression's risk factors and its preventive action. These risk factors lead to this disease such as remote learning and financial stress, relationship issues, health issues, and lifestyle changes.

Focusing on mental health risks such as depression is crucial to maximizing undergraduates' potential in relationships with peers and families, as well as overcoming future challenges (Islam et al., 2018). Undergraduates who experience parental disconnection, drink alcohol, school-based bullying or smoke are more prone to mental health risks such as depression and it is considered a big concern (Ashraful Islam et al., 2018). Recent events have demonstrated that undergraduates who suffer from mental health risks such as depression are more likely to experience numerous hospitalizations, repeated depressive episodes, psychosocial impairment, alcohol and drug misuse, violence, and anti-social behaviour (Yee et al., 2021).

\section{Prevention Behavior}

The issue of mental health risks such as depression among students is considered extremely serious; this imposes a significant public health burden, as it has already increased in numbers and can cause disability and even death (Sahril et al., 2019). One strategy for addressing this disease burden is through prevention. Through the use of youth-designed and youthimplemented mental health risks such as depression awareness and outreach activities, the intervention increases mental health risks such as depression literacy, which may result in earlier detection of mental health risks such as depression and fewer mental health risks such as depression sequelae (Parikh et al., 2018). Therefore, efforts to prevent and control mental health risks such as depression must begin by increasing public awareness as well as the undergraduate student and making changes in their lifestyle towards a healthier one. Cao et al (2021) study provides evidence for the importance of a combination of healthy lifestyle factors in preventing mental health risks such as depression, as well as reaffirming the significant potential of primary prevention. Concerning behaviour change, it entails several factors and stimuli from within the self to act in order to effect behaviour change, particularly in the behaviour of mental health risks such as depression prevention.

It is discovered that the person's attitude has an effect on behavioural intention. Self-efficacy leads to formation of intention, which results in behaviour change (Da et al., 2019; Rohani et al., 2018; Tang et al., 2021). However, Kirsch (1985) contends that self-efficacy-related behaviour change is not so much a belief in one's ability to accomplish something as it is a willingness to do so. As a result, this research focuses on individuals' prevention of mental health risks such as depression through recognizing their self-efficacy. The structural model below predicts self-efficacy in relation to preventative behaviour. The purpose of this study is to analyze the factors that influence the behavior of prevention of mental health risks such as depression by partially adopting the theory of Health Action Process Approach (HAPA). 


\section{Health Action Process Approach (HAPA)}

The Health Action Process Approach (HAPA) is employed as a theoretical framework in this study to empirically evaluate whether or not individuals' behaviour will employ preventative measures against mental health risks such as depression. Many surveys have employed HAPA to identify psychological determinants of health behaviours (Rohani et al., 2018). There are many studies using HAPA on physical activity and eating, weight reducing, smoking cessation, dental health and food safety behaviour research. Hence, this study shall applies HAPA which focuses on the part of motivational phase: self-efficacy in identifying the preventative mental health risks such as depression behaviour among the undergraduates.

\section{Self-Efficacy towards Preventive Behaviour}

Self-efficacy refers to an individual's belief in his or her own ability to carry out the advised action. Information and skills' sources will improve an individual's self-efficacy. According to Schwarzer (2016), self-efficacy is defined as one's confidence in being capable of performing specific behaviour. Individuals who have a high level of self-efficacy in controlling their good lifestyle should be more inclined to engage in preventive activity (Bandura, 1982) and initiate new behaviours (Schwarzer, 2016). Tamjidyamcholo, Baba, , Gholipour, and Yamchello (2013) noted that a high level of self-efficacy in an individual will increase their confidence in their abilities and motivate them. High self-efficacy has been found to be a good predictor of health promotion behaviours such as healthful diet (Rohani et al., 2018)and excessive Internet use (Tang et al., 2021). Perceived such sources which are helpful to increase the perceived abilities of people in preventive behaviour towards mental health risks such as depression. Thus, we anticipate that individuals with high levels of self-efficacy believe they are capable of coping with mental health risks such as depression risks. Thus, this research proposes the following hypothesis:

\section{H1: Self-efficacy have direct relationship to preventive mental health risks such as depression behavior}

\section{Action Planning towards Preventive Behaviour}

Schwarzer (2016) suggests that action planning is more effective than simply forming intentions since behavior is more likely to be elicited when relevant situational cues are encountered. A task-facilitating strategy that relates to how individuals prepare themselves in performing a behavior (Hamilton et al., 2020). In the current model of HAPA, action planning was expected to mediate intention-behavior effects, implying that planning is a critical component of the process behavior (Hamilton et al., 2020). However, in this study, we examine the role of action planning in promoting preventive behaviour in the absence of any control variable. Thus, this research proposes the second hypothesis:

\section{H2 Action planning has a positive relationship with preventive behavior}

\section{Self-Efficacy towards Action Planning}

Numerous individual's belief in their ability that they are capable of carrying out their actions. However, without planning, the belief cannot be carried out. Thus, the relationship of action planning and self-efficacy with behavior can be interpreted as bidirectional (Koring et al., 2012). With an increased self-efficacy, a more detailed plan will be created to carry out the preventive behavior. Thus, this research proposes the third hypothesis:

\section{H3 Self Efficacy has a positive relationship with action planning}




\section{Methodology}

This research applied a self-administered questionnaire in collecting the data. This research used the SmartPLS3.4 to analyze the data. The distribution of questionnaires up to 650 to the millennials age range of respondents and a total number of valid responses was 186 responses. The response rate was 28.6 percent.

\section{Results and Discussion}

The demographic results showed that more than half of the sample (81.7\%) was from female respondents and $95.7 \%$ of overall respondents came from the age $18-25$ years old. The demographic data of the respondents showed that all of the respondents come from a diverse educational background. More than 68 percent of the respondents were diploma holders and the rest came from undergraduates and postgraduates' level.

\section{Assessment on Reflective Measurement Model}

All item loadings were greater than 0.70 and significant at the 0.01 level, indicating convergent validity at the indicator level. All average variance extracted (AVE) values were greater than 0.50 , suggesting convergent validity at the construct level. A measurement model has satisfactory internal consistency reliability when the composite reliability (CR) of each construct exceeds the threshold value of 0.7 . All CR values that are greater than 0.70 indicate an acceptable reliability. Thus, the results indicate that the items used to represent the constructs have satisfactory internal consistency reliability.

Table 1: Fornell-Larcker Criterion

\begin{tabular}{|llll|}
\hline & Action planning & Preventive behaviour & Self efficacy \\
\hline Action planning & 0.826 & & \\
\hline Preventive behaviour & 0.457 & 0.836 & \\
\hline Self efficacy & 0.566 & 0.620 & 0.793 \\
\hline
\end{tabular}

Based on Table 1, the off-diagonal elements are lower than square roots of AVE (bolded on the diagonal). Hence, the result indicates an adequate discriminant validity for all of the reflective constructs. As for table 2, the HTMT criterion also indicates that the confidence interval does not show the value of 1 on any of the constructs which also confirms discriminant validity.

Table 2: Heterotrait-Monotrait Ratio (HTMT)

\begin{tabular}{|lll|}
\hline & $\begin{array}{l}\text { Action } \\
\text { planning }\end{array}$ & $\begin{array}{l}\text { Preventive } \\
\text { behaviour }\end{array}$ \\
\hline Action planning & & \\
\hline Preventive behaviour & 0.519 & \\
\hline Self efficacy & 0.629 & 0.711 \\
\hline
\end{tabular}

\section{Assessment of Structural Model}

Three direct hypotheses are developed between the constructs. T- statistics for all paths are generated via SmartPLS3.4 bootstrapping analysis. Two out of three hypotheses are found to have $t$-value $\geq 1.645$, thus significant at 0.05 level namely self-efficacy construct is positively related on preventive behavior $(\beta=0.532, p<0.01)$ and as well as self-efficacy construct also positively related on action planning construct by $\beta=0.566, p<0.01)$. On the other hand, action 
planning is positively related to preventive behaviour but not at significant level $(\beta=-0.157$, $\mathrm{p}<0.01$ ), hence the $\mathrm{H} 2$ is not supported. Thus, $\mathrm{H} 1$ and $\mathrm{H} 3$ are supported.

Henseler, Ringle, \& Sinkovics (2009) indicates that moderate or average $R^{2}$ values are acceptable when the endogenous construct is explained by few exogenous constructs. For this research, preventive behaviour explained $40.2 \%$ of the variance in action planning with $\mathrm{R}^{2}=0.402$, which is considered as substantial and self-efficacy is able to explain 0.32 of the variances in action planning which is also considered to be substantial (Cohen, 2013). The $f^{2}$ value of 0.471 indicates self-efficacy has a substantial effect in producing the $\mathrm{R}^{2}$ for action planning. On the other hand, the $f^{2}$ value of 0.028 indicates action planning has a weak effect in producing the $\mathrm{R}^{2}$ for preventive behaviour. The predictive relevance $\left(\mathrm{Q}^{2}\right)$ of action planning has a value of greater than 0 which stands at 0.211 , and preventive behaviour also stated at 0.264 which indicates that the model has a medium predictive relevance for two endogenous constructs as predictive relevance $\left(\mathrm{Q}^{2}\right)$ should stand above zero (Hair Jr, Sarstedt, Hopkins, \& Kuppelwieser (2014).

Table 3: Path coefficients, Observed t-statistics and results for all hypothesized path

\begin{tabular}{|l|l|l|l|}
\hline Hypotheses & $\begin{array}{l}\text { Path coefficient } \\
\text { (stdev) }\end{array}$ & $\begin{array}{l}\text { T statistics } \\
(\mid \text { o/stdev })\end{array}$ & Results \\
\hline $\begin{array}{l}\text { Action planning }->\text { preventive } \\
\text { behaviour }\end{array}$ & 0.157 & 1.340 & $\begin{array}{l}\text { Not } \\
\text { supported }\end{array}$ \\
\hline $\begin{array}{l}\text { Self-efficacy }->\quad \text { action } \\
\text { planning }\end{array}$ & 0.566 & 8.417 & Supported \\
\hline $\begin{array}{l}\text { Self-efficacy -> preventive } \\
\text { behaviour }\end{array}$ & 0.532 & 4.311 & Supported \\
\hline
\end{tabular}

Note: $*$ t-values $>1.645(\mathrm{p}<0.05) ; * *$ t-values $>2.33(\mathrm{p}<0.01)$ (one-tailed test)

Results from the study indicate that self-efficacy is one of the significant predictors in explaining the preventive behaviour towards mental health risks such as depression among undergraduate's student nowadays. This study supports the findings of (Yıldırım et al., 2021) who found that self-efficacy was positively and significantly correlated with preventive behaviour. This result, which explains the high self-efficacy, would lead to a high level of engagement in preventive behavior against mental health risks such as depression. Another study by Fathian-Dastgerdi et al (2021)also proved that correlation between self-efficacy and preventive behaviour. Thus, it demonstrates that establishing a preventive behaviour requires concerted efforts to reinforce one's belief in one's ability to behave in a particular way. Therefore, the results of this study provide evidence in support of interventions that enhance self-efficacy to promote healthy lifestyle to prevent mental health risks such as depression among undergraduate.

On the other hand, this study found that there is a positive but not a significant relationship between action planning and preventive behaviour. This result contrary with study by De Vries (2017) which stated the importance of action planning as determinants to behavior change. This discrepancy in findings regarding action planning and preventive behaviour may be explained by the fact that the majority of previous research has used action planning as a mediator to establish a link between self-efficacy and preventive behavior (Panahi \& Keikavoosi-arani, 2020; Pourhaji \& Ghofranipour, 2018). This result shows that action planning needs to be associate with the other variable to be significant influence the behavior. This may be the contribution and need to be further explain by the other studies. 
The other results from the study indicate that self-efficacy is one of the significant predictors in explaining the action planning towards mental health risks such as depression among undergraduate's student nowadays. This result consistent with study by (De Vries, 2017) which mentioned that demonstrate that action planning may only be beneficial for respondents with high self-efficacy. The HAPA's underlying concept is that health behaviour is determined by personal beliefs or perceptions about a disease/health condition and their support by available planning strategies to prevent its occurrence. Therefore, this study demonstrates that self-efficacy predicts action planning in order to carry out the behaviour. Thus, the greater one's self-efficacy, the more action plans will be implemented to prevent the mental health risks such as depression.

\section{Conclusion}

In this paper, the study purposely adopting the HAPA theory as to clearly explained an alternative avenue on predicting the possible preventive behavior towards mental health risks such as depression risk. It has becoming much more obvious especially in the era of COVID 19, our youngsters are no exception being part of parties that trapped within the cluster of mental health. The external environment and standard procedure that only allow us to limit our space within the compound of our house and nearby area also did not provide an escape or relief of mind to our nature as human. This research framework also provides significant variables that shows how to go about in a situation that we faced nowadays especially within the research setting that we focus into. Thus, it is recommended for future researchers to develop an empirical study on the proposed theoretical framework with additional setting that can contribute towards the body of knowledge. It is very important that in light of current pandemic situations are one of the many situations that the issues such as health risks particularly mental health risks such as depression risk been given equal attention despite its intangible nature as to provide ways to overcome this in our communities as it does not bode well with our future as a nation if this become one of main risks that we might have to combat too. In light of these research findings, this study was recommended for future research to ascertain the prevalence of mental health risks such as depression and its prevention among Malaysian undergraduates as well as other settings. Additionally, this study aimed to determine the relationship between self-efficacy, healthy lifestyle planning, and mental health risks such as depression prevention among students in this age group, in order to identify high-risk groups and prevent further increases in mental health risks such as depression cases and behaviour risk.

This paper will contribute to enlightening the issue related to individual preventive behavior action to have a well-being mental health. It can brighten an individual in taking a right and manner action related to their mental health. As well as provide important information towards society as a whole such as family and community in helping their surroundings behave or act wisely. It gives significant attributes to the body of knowledge and the researchers in providing knowledge that could benefit all.

\section{Declaration of Conflict of Interest}

None

\section{Funding Acknowledgement}

This research is supported by University Technology Mara (UiTM) under TEJA Grant (GDT2021/1-15). 


\section{References}

Islam, A. M., Low, Y. W., Tong, T. W., Yuen, W. C. C., \& Abdullah, A. (2018). Factors Associated with Depression among University Students in Malaysia: A Cross-sectional Study. KnE Life Sciences, 4(4), 415. https://doi.org/10.18502/kls.v4i4.2302

Bandura, A. (1982). Self-efficacy mecha- nisms in human agency. American Psychologist, 37, 122-147.

Bernama. (2018). Resolving mental illness issues in Malaysia Online Course . Virtual training Led by Industry Experts. Thesundaily, 1-9.

https://www.thesundaily.my/archive/resolving-mental-illness-issues-malaysiaYUARCH541062

Cao, Z., Yang, H., Ye, Y., Zhang, Y., Li, S., Zhao, H., \& Wang, Y. (2021). Polygenic risk score, healthy lifestyles, and risk of incident depression. Translational Psychiatry, 11(1), 1-9.

Cohen, J. (2013). Statistical power analysis for the behavioral sciences. Academic press.

Da, W., Qiao, S., \& Li, X. (2019). Applying the Health Action Process Approach (HAPA) in Program Evaluation of a Theory-Based Parental HIV Disclosure Intervention among Parents Living with HIV (PLH) in China. 27549175, 120.

https://www.proquest.com/dissertations-theses/applying-health-action-processapproach-hapa/docview/2382812130/se-

2 ?accountid=27446\%0Ahttp://www.yidu.edu.cn/educhina/educhina.do ?artifact=\&sva lue=Applying+the+Health+Action+Process+Approach+\%28HAPA\%29+in+Pro

De Vries, H. (2017). An integrated approach for understanding health behavior; the I-change model as an example. Psychol Behav Sci Int J, 2(2), 555-585.

DrImranHafidz. (2014). Dealing with mental health emergencies. Developing Healthcare Skills Through Simulation. https://doi.org/10.4135/9781446269954.n13

Eriksson, N., Gökhan, A., \& Stenius, M. (2021). A qualitative study of consumer resistance to mobile payments for in-store purchases. Procedia Computer Science, 181(2019), 634641. https://doi.org/10.1016/j.procs.2021.01.212

Fathian-Dastgerdi, Z., khoshgoftar, M., Tavakoli, B., \& Jaleh, M. (2021). Factors associated with preventive behaviors of COVID-19 among adolescents: Applying the health belief model. Research in Social and Administrative Pharmacy, 17(10), 1786-1790. https://doi.org/10.1016/j.sapharm.2021.01.014

Ferrer, R. A., \& Klein, W. M. P. (2015). Risk perceptions and health behavior. Current Opinion in Psychology, 5, 85-89. https://doi.org/10.1016/j.copsyc.2015.03.012

Hair Jr, F., J., Sarstedt, M., Hopkins, L., \& G. Kuppelwieser, V. (2014). Partial least squares structural equation modeling (PLS-SEM). European Business Review, 26(2), 106-121.

Hamilton, K., Smith, S. R., Keech, J. J., Moyers, S. A., \& Hagger, M. S. (2020). Application of the Health Action Process Approach to Social Distancing Behavior During COVID-19. Applied Psychology: Health and Well-Being, 12(4), 1244-1269.

https://doi.org/10.1111/aphw.12231

Henseler, J., Ringle, C. M., \& Sinkovics, R. R. (2009). The Use of Partial Least Squares Path Modelling in International Marketing. Advances in International Marketing, 20(1), 277319.

Khan, T. M., Sulaiman, S. A., Hassali, M. A., \& Tahir, H. (2009). Attitude toward depression, its complications, prevention and barriers to seeking help among ethnic groups in Penang, Malaysia. Mental Health in Family Medicine, 6(4), 219-227.

Kirsch, I. (1985). Self-efficacy and ex- pectancy: old wine with new labels. No Title. Journal of Personality and Social Psychology, 49(3),(3), 824-830. 
https://doi.org/https://doi.org/10.1037/0022-3514.49.3.824

Koring, M., Richert, J., Parschau, L., Ernsting, A., Lippke, S., \& Schwarzer, R. (2012). A combined planning and self-efficacy intervention to promote physical activity: A multiple mediation analysis. Psychology, Health and Medicine, 17(4), 488-498.

https://doi.org/10.1080/13548506.2011.608809

NHMS. (2018). National Health and Morbidity Survey (NHMS) 2017 : Key Findings from the Adolescent Health and Nutrition Surveys; Infographic Booklet. In Institute for Public Health, National Institutes of Health, The Ministry of Health, Malaysia (Issue April).

NHMS. (2019). Key findings (Vol. 20). https://doi.org/10.18356/be4d1601-en

Panahi, H., \& Keikavoosi-arani, L. (2020). Sunscreen use : a theory-based interventional study using HAPA. Health Education, 120(3), 217-227.

Parikh, S. V., Taubman, D. S., Antoun, C., Cranford, J., Foster, C. E., Grambeau, M., Hunter, J., Jester, J., Konz, K., Meyer, T., Salazar, S., \& Greden, J. F. (2018). The Michigan peer-toPeer depression awareness program: School-Based prevention to address depression among teens. Psychiatric Services, 69(4), 487-491. https://doi.org/10.1176/appi.ps.201700101

Pourhaji, F., \& Ghofranipour, F. (2018). Designing and psychometric evaluation of breast selfexamination behavior predicting scale (BSEBPS). International Journal of Cancer Management, 11(12).

Rohani, H., Bidkhori, M., Eslami, A. A., Sadeghi, E., \& Sadeghi, A. (2018). Psychological factors of healthful diet promotion among diabetics: an application of health action process approach. Electronic Physician, 10(4), 6647-6654. https://doi.org/10.19082/6647

S. Othman, and A. C. Essau. (2019). Adolescent health risk behaviors and mental health: evidence from the Malaysian National Health and Morbidity Survey 2017 ,. Asia Pacific Journal of Public Health, 31(8), 6S - 75.

Sahril, N. B., Yaacob, N. M., Ahmad, N. A., Abdullah, S., Naidu, M. B., \& Aris, T. (2019). Depression Severity and its Associated Factors among School-Going Adolescents in Malaysia. Journal of Depression and Anxiety, 08(04), 1-8. https://doi.org/10.35248/2167-1044.19.8.350

Schwarzer, R. (2016). Health Action Process Approach ( HAPA) as a Theoretical Framework to Understand Behavior Change. Actualidades En Psicologia, 30(121), 119-130.

Tahmassian, K., \& Moghadam, N. J. (2011). Relationship between self-efficacy and symptoms of anxiety, depression, worry and social avoidance in a normal sample of students. Iranian Journal of Psychiatry and Behavioral Sciences, 5(2), 91-98.

Tamjidyamcholo, A., Baba, A. S. B., Gholipour, R., and Yamchello, H. T. (2013). Information Security Professional Perceptions of Knowledge-Sharing Intention in Virtual Communities under Social Cognitive Theory. Research and Innovation in Information Systems.

Tang, C., Raat, H., Yan, M., Zhang, Q., Li, K., Jiang, M., Tang, W., Chen, J., Zhao, Y., \& Liu, Q. (2021). Application of the health action process approach model for reducing excessive internet use behaviors among rural adolescents in China: a school-based intervention pilot study. BMC Public Health, 21(1), 1-17. https://doi.org/10.1186/s12889-02110999-z

Yee, A., Hodori, N. 'Aqilah M., Tung, Y. Z., Ooi, P. L., Latif, S. A. B. A., Isa, H. M., Ng, D. L. C., Chai, C. S., \& Tan, S. B. (2021). Depression level and coping responses toward the movement control order and its impact on quality of life in the Malaysian community during the COVID-19 pandemic: a web-based cross-sectional study. Annals of General 
INTERNATIONAL JOURNAL OF ACADEMIC RESEARCH IN BUSINESS AND SOCIAL SCIENCES

Vol. 12, No. 1, 2022, E-ISSN: 2222-6990 @ 2022 HRMARS

Psychiatry, 20(1), 1-9. https://doi.org/10.1186/s12991-021-00352-4

Yıldırım, M., Geçer, E., \& Akgül, Ö. (2021). The impacts of vulnerability, perceived risk, and fear on preventive behaviours against COVID-19. Psychology, Health \& Medicine, 26(1), $35-43$. 